\title{
SEGUNDO ENCUENTRO NACIONAL DE SEMILLEROS
}

\author{
Guillermo Sánchez V. MD*
}

La Fundación Universitaria de Ciencias de la Salud a través de diferentes estrategias y cumpliendo con su objeto misional, ha decidido liderar diferentes iniciativas que la consoliden como una institución a la vanguardia de la investigación en salud. Dentro de este programa de fortalecimiento de la investigación queremos trascender no solo por las contribuciones al interior de la Fundación, sino que deseamos hacer parte de los cambios nacionales que en este campo necesita el país.

Con el paso del tiempo y a través de diferentes experiencias, en la FUCS hemos comprendido que el país necesita formar capital humano idóneo, capaz de enfrentar los retos de la ciencia, la tecnología y la innovación. Pero esta iniciativa debe ser parte de un proceso constante, sólido y consistente, que no puede darse solo a nivel de posgrados, maestrías y doctorados, sino que debe forjarse desde los primeros años de formación. Es en ese sentido que la FUCS ha entendido que es imprescindible generar espacios de apoyo a los semilleros de investigación y ofrecer para ellos escenarios de alta calidad académica y científica, en los cuales sea posible difundir a la comunidad interesada el desarrollo que ha venido logrando la investigación formativa en el país.

Consecuentes con estos planteamientos, desde el año 2011 nos dimos a la tarea de estructurar un evento de alcance nacional, que permitiera a los estudiantes de pregrado presentar los resultados de sus trabajos de investigación. Fue grata nuestra sorpresa al ver que la mayoría de las facultades de medicina del país y muchas otras del área de la salud, acogieron nuestra propuesta. Esto nos permitió desarrollar con total éxito la primera versión del "Encuentro Nacional de Semilleros de Investigación- Facultades de medicina: ENSI".

* Director de la División de Investigaciones, Fundación Universitaria de Ciencias de la Salud. Bogotá DC. Colombia.
Realizamos la segunda versión del ENSI, los días 24, 25 y 26 de julio de 2013 en el auditorio de la Cámara de Comercio de Bogotá-Sede Salitre. En esa ocasión superamos los logros del 2012; contamos con la presencia de 41 facultades, 102 grupos de semilleros de investigación de medicina de todo el país y más de mil participantes. Recibimos 230 trabajos de excelente calidad que participaron en las categorías de presentación oral, póster y póster electrónico.

En el evento tuvimos el gusto de compartir con conferencistas internacionales y nacionales reconocidos. Para la sesión de apertura, tuvimos el privilegio de escuchar al doctor Jorge Reynolds, director del Grupo de Seguimiento al Corazón Vía Satélite; desde España nos visitó el doctor Ángel Carracedo Álvarez, Director de la Fundación Pública Gallega de Medicina Genómica y del Instituto de Medicina Legal de la USC de España; del Perú nos acompañó la doctora Rosa Luz Pacheco, Directora General de Investigación de la ANR Perú. También contamos con la participación del doctor Juan Manuel Lozano, médico colombiano, profesor de la Universidad Internacional de la Florida, y la Doctora Martha Gómez, investigadora colombiana, radicada en New Orleans donde trabaja como Senior Scientist en el Audubon Center for Research of Endangered Species.

Además de la importancia de tener un escenario como el ENSI, en la FUCS estamos convencidos de la necesidad de contar en el país con una red nacional de semilleros de investigación de las facultades de medicina. En consecuencia, las directivas de la FUCS y la División de Investigaciones, hemos propuesto el tercer ENSI para julio de 2015 y durante 2014 realizaremos la tercera reunión de la red nacional de semilleros de investigación de facultades de medicina, de tal suerte que al finalizar el año tengamos sentadas las bases definitivas de la red y un programa de trabajo conjunto. 
Extendemos nuestra invitación para que todas las facultades de medicina interesadas nos acompañen en la reunión de la rẹd programada para julio 2014 y que nuestros semilleros preparen sus trabajos de investigación para presentarlos en el III ENSI, programado para julio de 2015. Por último aprovechamos la oportunidad para agradecer el apoyo irrestricto de las Directivas de la FUCS, su Consejo Superior, la Rectoría y la Vicerrectoría Académica. El II ENSI no hubiera sido un éxito sin el apoyo de los estudiantes de semilleros de investigación de la FUCS; agradece- mos la colaboración de todas las facultades y de las áreas de educación continuada, ambientes virtuales, audiovisuales, servicios administrativos, mercadeo y las demás dependencias de la Fundación.

Un fuerte abrazo y un agradecimiento a la División de Investigaciones de la FUCS, al equipo de gestión de conocimiento, al equipo logístico y a todos los docentes. Esperemos que el tercer encuentro de la Red programado para el 2014 y el III ENSI del 2015, logren el éxito de los eventos que los han precedido. 